\title{
Papers
}

\section{Assessment of independent effect of olanzapine and risperidone on risk of diabetes among patients with schizophrenia: population based nested case-control study}

\author{
Carol E Koro, Donald O Fedder, Gilbert J L'Italien, Sheila S Weiss, Laurence S Magder, \\ Julie Kreyenbuhl, Dennis A Revicki, Robert W Buchanan
}

\begin{abstract}
Objective To quantify the association between olanzapine and diabetes.

Design Population based nested case-control study. Setting United Kingdom based General Practice Research Database comprising 3.5 million patients followed between 1987 and 2000.

Participants 19637 patients who had been diagnosed as having and treated for schizophrenia. 451 incident cases of diabetes were matched with 2696 controls. Main outcome measures Diagnosis and treatment of diabetes.

Results Patients taking olanzapine had a significantly increased risk of developing diabetes than non-users of antipsychotics (odds ratio 5.8, 95\% confidence interval 2.0 to 16.7 ) and those taking conventional antipsychotics (4.2, 1.5 to 12.2). Patients taking risperidone had a non-significant increased risk of developing diabetes than non-users of antipsychotics (2.2, 0.9 to 5.2) and those taking conventional antipsychotics (1.6, 0.7 to 3.8).

Conclusion Olanzapine is associated with a clinically important and significant increased risk of diabetes.
\end{abstract}

\section{Introduction}

Since the late 1980s new antipsychotic agents with different mechanisms of action from conventional antipsychotics have been developed and widely adopted in the treatment of schizophrenia. The main advantage of these newer antipsychotics is a reduction of extrapyramidal side effects ${ }^{1}$; however, they are associated with a different spectrum of side effects, including weight gain, alterations in glucose metabolism, increased concentrations of blood cholesterol and lipids, myocarditis, and cardiomyopathy. ${ }^{2-5}$ These metabolic effects may pose a burden as serious as the extrapyramidal effects. ${ }^{6}$

Recent evidence has shown an association between olanzapine and diabetes. ${ }^{7-14}$ Most of the articles were case reports documenting the incidence of diabetes or hyperglycaemia with olanzapine. No such case reports exist for risperidone, despite this drug being introduced three years before olanzapine and having a similar share of the market. Hyperglycaemia is listed as an "infrequent" side effect of both olan- zapine and risperidone and diabetes mellitus as an "infrequent" metabolic and nutritional side effect of risperidone. The degree to which these drugs are associated with the incidence of diabetes has not, however, been established.

Drugs known to affect the risk of diabetes include $\alpha$ adrenergic blockers, $\beta$ adrenergic blockers, thiazide diuretics, corticosteroids, phenytoin, oral contraceptives containing norgesterol, and valproate. ${ }^{15-17}$ We used data from the United Kingdom based General Practice Research Database to quantify the risk of diabetes associated with conventional and newer generation antipsychotics, specifically olanzapine and risperidone. We aimed to assess the independent effect of these drugs on the risk of diabetes in patients with schizophrenia.

\section{Methods}

\section{Study population}

Our study population comprised patients with a recorded doctor diagnosis of and drug treatment for schizophrenia registered with medical practices in the General Practice Research Database between June 1987 and September 2000. The database is described elsewhere. ${ }^{18}$ Briefly, it contains data from around 400 general practices, dealing with 3.5 million patients in England and Wales. Continuous information has been collected for over 10 years, providing more than 30 million patient years of observation. ${ }^{19}$ We derived our data from patient registration records, medical records, and prescription records stored in the database. The source of the database in our study is the Epidemiology and Pharmacology Information Core. Our study protocol was approved by the Scientific and Ethical Advisory Group of the database.

\section{Cohort}

Patients were eligible from the time that up to standard data were provided for them in the database - that is, the data recording had reached a standard appropriate for research use. In addition, all previous diagnoses and treatments are recorded in the medical records. Eligibility criteria for our study included a diagnosis of and treatment for schizophrenia recorded at any time. We defined the study period for patients identified as

\author{
Pharmaceutical \\ Health Services \\ Research \\ Department, School \\ of Pharmacy, \\ University of \\ Maryland, \\ Baltimore, MD \\ 21201, USA \\ Carol E Koro \\ postgraduate \\ Pharmacy Practice \\ and Science, \\ University of \\ Maryland \\ Donald O Fedder \\ professor \\ Sheila S Weiss \\ assistant professor \\ Epidemiology and \\ Preventive \\ Medicine, School of \\ Medicine, \\ University of \\ Maryland \\ Laurence S Magder \\ associate professor \\ VA Capital Network \\ Mental Illness \\ Research, \\ Education, and \\ Clinical Center, \\ University of \\ Maryland \\ Julie Kreyenbuhl \\ assistant professor \\ Maryland \\ Psychiatric \\ Research Center, \\ University of \\ Maryland \\ Robert W \\ Buchanan \\ professor \\ continued over
}

bmj.com 2002;325:243 
Decision Sciences

Outcomes

Research,

Bristol-Myers

Squibb

Pharmaceutical

Research Institute,

Wallingford, CT

06492, USA

Gilbert J L'Italien

director

Center for Health

Outcomes

Research, MEDTAP

International,

Bethesda, MD

20814, USA

Dennis A Revicki

chairman of board

Correspondence to:

C E Koro

ckoro001@

umaryland.edu

\section{Selection of participants}

Cases

Incident cases of diabetes were defined as the earliest date of a diagnosis of or treatment for diabetes, occurring at least three months after the beginning of the study period. We define the date for diagnosis as the index date. To ensure that the patients with diabetes were incident cases, we checked the medical and prescription records for any diagnosis of or treatment for diabetes before the study began. Patients identified as cases should not have had a prescription for insulin or oral antidiabetic agents within three months of the index date. The use of a three month window avoided the exclusion of patients with diabetes who contributed no more than three months of data. However, $97 \%$ of the cases were free of diabetes for six months or more.

\section{Controls}

For each case we matched six controls with study periods at least as long as that of the case by age at index date (SD 5 years), sex, and index date. Controls that met the matching criteria were selected at random with SAS software. Controls were selected from patients who had been diagnosed as having or treated for schizophrenia but not diagnosed as having or treated for diabetes at any time. Controls were assigned the

Table 1 Characteristics of study population and incident cases of diabetes. Values are numbers (percentages)

\begin{tabular}{lcc} 
& $\begin{array}{c}\text { Study population } \\
(\mathbf{n}=\mathbf{1 9} \mathbf{6 3 7})\end{array}$ & $\begin{array}{c}\text { Incident cases of diabetes } \\
\mathbf{( n = 4 5 1 )}\end{array}$ \\
\hline Age (years) & $487(2.5)$ & $2(0.4)$ \\
\hline$<20$ & $7854(40.0)$ & $74(16.4)$ \\
\hline $20-44$ & $5693(29.0)$ & $191(42.4)$ \\
\hline $45-64$ & $5603(28.5)$ & $184(40.8)$ \\
\hline Sex & & $169(37.5)$ \\
\hline Male & $9522(48.5)$ & $282(62.5)$ \\
\hline Female & $10115(51.5)$ & $382(84.7)$ \\
\hline Ever use of antipsychotics* & & $339(75.2)$ \\
\hline Conventional antipsychotics: & $18443(93.9)$ & $95(21.1)$ \\
\hline Non-depot & $17320(88.2)$ & $9(2.0)$ \\
\hline Depot & $4421(22.5)$ & $23(5.1)$ \\
\hline Olanzapine & $970(4.9)$ & $6(1.3)$ \\
\hline Risperidone & $1683(8.6)$ & \\
\hline Other newer agents & $578(2.9)$ & \\
\hline
\end{tabular}

${ }^{\star}$ Categories not mutually exclusive. Ever use is at least one prescription for drug of interest, with prescription date any time during study period. same index date as the cases to which they were matched. Therefore the calendar time distributions of the index date were the same for both cases and controls.

\section{Drug use}

We classified antipsychotics as conventionals (depot or non-depot), olanzapine, risperidone, and other newer drugs. Non-depot conventional antipsychotics included benperidol, chlorpromazine, droperidol, flupenthixol, fluphenazine, haloperidol, loxapine, methotrimeprazine, oxypertine, pericyazine, perphenazine, pimozide, prochlorperazine promazine, sulpiride, thioridazine, trifluoperazine, trifluperidol, and zuclopenthixol. Depot conventional antipsychotics included flupenthixol decanoate, fluphenazine decanoate, fluphenazine enanthate, fluspirilene, haloperidol decanoate, and pipothiazine palmitate. Other newer antipsychotics included amisulpiride, remoxipride, and sertindole.

We abstracted all prescriptions written by the doctor for the treatment of schizophrenia and diabetes between the start of the study period and the index date. We defined drug use as the receipt of at least one prescription for an antipsychotic within three months of the index date. The selection of a three month window was based on a review of the case reports suggesting a mean time to onset of glucose dysregulation of three months after starting olanzapine. ${ }^{7-14}$ Patients not taking the drugs of interest were those who did not have a prescription for an antipsychotic within three months of the index date.

\section{Statistical analysis}

We conducted all analyses with SAS version 7.0. Our main study comprised a nested case-control analysis. To account for the matched study design, we modelled the effect of drug use on the risk of diabetes development using conditional logistic regression. ${ }^{20}$

We used different referent groups to compare the risk of diabetes developing among users of the different antipsychotics. The first group included all patients except those receiving the drug of interest. The second group included patients taking conventional antipsychotics. The third group included patients with no prescription for an antipsychotic within three months of the index date. In addition to the matching variables, we adjusted the analysis for use of other drugs known to affect the risk of diabetes, such as $\alpha$ blockers, $\beta$ blockers, thiazide diuretics, corticosteroids, phenytoin, oral contraceptives containing norgesterol, and valproate.

\section{Results}

\section{Cohort analysis}

Between 1 June 1987 and 24 September 2000, 21145 patients were diagnosed as having and treated for schizophrenia. We excluded 916 of these with less than three months' follow up, 582 diagnosed as having or treated for diabetes before the start of their follow up period, and 10 with no information on diabetes diagnosis or treatment dates. This left 19637 patients for study.

Males and females were equally represented in the study population, with a mean age of 51 (SD 20) years (table 1). Overall, $17320(88.2 \%)$ had at least one pre- 
scription for non-depot conventional antipsychotics, $4421(22.5 \%)$ for depot conventional antipsychotics, $970(4.9 \%)$ for olanzapine, $1683(8.6 \%)$ for risperidone, and $578(2.9 \%)$ for other newer antipsychotics.

In total, 451 patients developed diabetes during a mean follow up of 5.2 (SD 3) years. The incidence rate of diabetes among all patients with schizophrenia treated with antipsychotics was $4.4 / 1000$ person years. Women exhibited a higher incidence rate than men (5.3 $v 3.5 / 1000$ person years). The incidence rate within three months of a prescription was $10.0 / 1000$ person years for olanzapine $(95 \%$ confidence interval 5.2 to 19.2$), 5.4 / 1000$ person years for risperidone (3.0 to 9.8 ), and $5.1 / 1000$ person years for conventional antipsychotics (4.5 to 5.8).

\section{Case-control analyses}

We matched 451 cases of diabetes with 2696 controls. Three patients had fewer than six controls per case, totalling 10 missing controls. The age and sex of the cases and controls were similar (table 2). The prevalence of conventional antipsychotic use differed among the cases and controls and among olanzapine users but not among risperidone users (table 2).

The risk of diabetes was greatest among olanzapine users (odds ratio 4.4, 1.8 to 11.0 ; table 3); use of conventional antipsychotics slightly increased the risk (1.3, 1.1 to 1.6). Use of risperidone was also associated with a slightly increased risk of diabetes (1.6, 0.8 to 3.3), but this was not significant (table 3).

Compared with no antipsychotic use olanzapine significantly increased the risk of diabetes (adjusted odds ratio 5.8, 2.0 to 16.7; table 4), followed by risperidone (2.2, 0.9 to 5.2$)$ and conventional antipsychotics (1.4, 1.1 to 1.7$)$. Olanzapine was associated with a significantly increased risk of diabetes $(4.2,1.5$ to 12.2$)$
Table 2 Characteristics of cases and controls. Values are numbers (percentages)

\begin{tabular}{lcc} 
Characteristics & Cases $\mathbf{( n = 4 5 1 )}$ & Controls $(\mathbf{n}=\mathbf{2 6 9 6})$ \\
\hline Age (years): & $2(0.4)$ & \\
\hline$<20$ & $74(16.4)$ & $14(0.5)$ \\
\hline $20-44$ & $191(42.4)$ & $1158(43.0)$ \\
\hline $45-64$ & $184(40.8)$ & $1084(40.2)$ \\
\hline$\geqslant 65$ & & \\
\hline Sex: & $282(62.5)$ & $1687(62.6)$ \\
\hline Female & $169(37.5)$ & $1009(37.4)$ \\
\hline Male & & $1428(53.0)$ \\
\hline Use of antipsychotic within 3 months of index date*: & $268(59.4)$ & $15(0.6)$ \\
\hline Conventional antipsychotics & $9(2.0)$ & $42(1.6)$ \\
\hline Olanzapine & $11(2.4)$ & $7(0.3)$ \\
\hline Risperidone & $1(0.2)$ & \\
\hline Other newer agents &
\end{tabular}

${ }^{*}$ Categories not mutually exclusive.

compared with conventional antipsychotics, unlike risperidone (1.6, 0.7 to 3.8 ; table 4).

\section{Discussion}

After adjustment for personal risk factors and concomitant drug use, patients taking conventional or newer antipsychotics for schizophrenia have an increased risk of diabetes. The risk was significantly increased with the newer antipsychotic olanzapine but not with the other newer antipsychotic, risperidone. Our study is the first to show these associations in a large cohort of patients with schizophrenia.

Several mechanisms are proposed for the observed association between diabetes and antipsychotic use, including weight gain and disruption of glucose metabolism. A meta-analysis showed a mean increase in weight of $4.15 \mathrm{~kg}$ for patients taking olanzapine and $2.10 \mathrm{~kg}$ for those taking risperidone. ${ }^{2}$ Type 2 diabetes

Table 3 Exposure odds ratios and 95\% confidence intervals for development of diabetes in patients using different classes of antipsychotics within 3 months of index date compared with patients not taking drug of interest. Values are numbers (percentages) unless stated otherwise

\begin{tabular}{|c|c|c|c|c|c|c|}
\hline Antipsychotic & Cases $(n=451)$ & Controls $(n=2696)$ & $\begin{array}{l}\text { Unadjusted odds ratio } \\
\qquad(95 \% \mathrm{CI})\end{array}$ & $P$ value & $\begin{array}{l}\text { Adjusted odds ratio } \\
(95 \% \mathrm{CI})^{\star}\end{array}$ & $P$ value \\
\hline Conventional antipsychotics: & $268(59.4)$ & $1428(52.9)$ & 1.3 (1.1 to 1.6$)$ & 0.009 & 1.3 (1.1 to 1.6$)$ & 0.013 \\
\hline Non-depot & $235(52.1)$ & $1269(47.1)$ & $1.2(1.0$ to 1.5$)$ & 0.043 & $1.2(1.0$ to 1.5$)$ & 0.051 \\
\hline Depot & $48(10.6)$ & $281(10.4)$ & $1.0(0.7$ to 1.4$)$ & 0.881 & $1.0(0.7$ to 1.4$)$ & 0.855 \\
\hline Olanzapine & $9(1.9)$ & $15(0.6)$ & 4.0 (1.7 to 9.5$)$ & 0.002 & $4.4(1.8$ to 11.0$)$ & 0.002 \\
\hline Risperidone & $11(2.4)$ & $42(1.6)$ & $1.6(0.8$ to 3.1$)$ & 0.177 & 1.6 (0.8 to 3.3$)$ & 0.160 \\
\hline Other newer antipsychotics & $1(0.2)$ & $7(0.3)$ & $0.9(0.1$ to 7.0$)$ & 0.885 & $0.7(0.1$ to 5.8$)$ & 0.723 \\
\hline
\end{tabular}

${ }^{*}$ Adjusted for age, sex, index year, duration of follow up, and use of either $\alpha$ blocker, $\beta$ blocker, $\beta$ blocker and thiazide diuretic, corticosteroid, thiazide diuretic lithium, oral contraceptives containing norgesterol, or valproate.

Table 4 Comparison of patients using olanzapine and risperidone within three months of index date with patients not using antipsychotics or those using conventional antipsychotics

\begin{tabular}{|c|c|c|c|c|}
\hline Antipsychotic* & Cases $(n=451)$ & Controls $(n=2696)$ & Adjusted odds ratio $(95 \% \mathrm{Cl}) \dagger$ & $P$ value \\
\hline No antipsychotics (reference) & 168 & 1228 & & \\
\hline Conventional antipsychotics & 263 & 1404 & 1.4 (1.1 to 1.7$)$ & 0.004 \\
\hline Olanzapine & 7 & 11 & $5.8(2.0$ to 16.7$)$ & 0.001 \\
\hline Risperidone & 7 & 26 & $2.2(0.9$ to 5.2$)$ & 0.079 \\
\hline Other newer agents & 1 & 3 & $1.6(0.2$ to 17.1$)$ & 0.699 \\
\hline Conventional antipsychotics (reference) & 263 & 1404 & & \\
\hline Olanzapine & 7 & 11 & $4.2(1.5$ to 12.2$)$ & 0.008 \\
\hline Risperidone & 7 & 26 & $1.6(0.7$ to 3.8$)$ & 0.290 \\
\hline Other newer agents & 1 & 3 & $1.2(0.1$ to 12.4$)$ & 0.900 \\
\hline
\end{tabular}

${ }^{*}$ Categories mutually exclusive. Results not shown for patients using more than one antipsychotic, included in model.

†Adjusted for age, sex, index year, duration of follow up, and use of either $\alpha$ blocker, $\beta$ blocker, $\beta$ blocker and thiazide diuretic, corticosteroid, thiazide diuretic, lithium, oral contraceptives containing norgesterol, or valproate. 


\section{What is already known on this topic}

Recent evidence has suggested an association between the newer class of antipsychotics and diabetes

Most of these studies were case reports

The association has not been confirmed in epidemiological studies, with the relation adjusted for comorbid factors

\section{What this study adds}

Olanzapine is associated with a clinically important increased risk of diabetes

After adjustment for relevant risk factors this association is significant

The metabolic consequences of olanzapine should be considered by doctors giving treatment

seems to be strongly and consistently associated with obesity and weight gain. ${ }^{21}{ }^{22}$ Antagonism of histamine is also known to cause weight gain. ${ }^{23}$ It is possible that serotonin antagonism plays a part in the weight gain associated with the newer drugs. ${ }^{25}$ Weight gain can also be due to increased leptin secretion, which in turn leads to a disturbance of insulin secretion and diabetes mellitus. ${ }^{12}$ Lastly, dopamine has been shown to stimulate insulin secretion by a $\beta$ adrenergic mediated mechanism. ${ }^{26} 27$

\section{Limitations of study}

Our study has several limitations. Drug use was inferred from automated prescribing data. Also, patient specific data were limited to that recorded in the database. However, one study showed that $95 \%$ of prescriptions and $74 \%$ of consultations in the General Practice Research Database were recorded on computer compared with $42 \%$ and $75 \%$ in written records. ${ }^{28}$ In addition, there was no direct information on the severity of schizophrenia, race, social class, or weight gain. We were thus unable to adjust for these variables. Confounding by indication remains a concern in observational pharmacoepidemiological studies. Clinicians may have prescribed one drug over the other based on the severity of the schizophrenia. We attempted to reduce this confounding by adjusting for known risk factors for diabetes. However, since confounders must be associated with both the use of the drug and the disease, we believe it is unlikely that the severity of schizophrenia would be linked to the incidence of diabetes. It was not possible to study the association between an important newer antipsychotic, clozapine, and diabetes as clozapine therapy must be started when patients are in hospital, and these patients are not included in the General Practice Research Database. Another limitation of our analysis was that we ignored the use of antipsychotics before the three month exposure period, therefore patients may have used different antipsychotics during the study period. Lastly, our analysis lacked power to compare the odds ratios between olanzapine and risperidone users.
Olanzapine use is consistently associated with a clinically important increased risk of diabetes, and this association, after adjustment for relevant risk factors, is significant. The metabolic consequences of antipsychotic therapy should be considered by treating doctors.

The General Practice Research Database is compliant with the Data Protection Act, 1998.

Contributors: CEK conceived the study, carried out the analysis, and drafted the paper. CEK, DOF, SSW, DAR, RWB, JK, LSM, and GJL planned and designed the study. CEK, SSW, and LSM reviewed the statistical analysis. RWB and DAR evaluated the results. All authors contributed to modifying the manuscript and the final editing of the paper. CEK and RWB will act as guarantors for the paper

Funding: Bristol-Myers Squibb provided the data from the General Practice Research Database for this study at no cost and without restriction.

Competing interests: GJL is an employee of Bristol-Myers Squibb, Pharmaceutical Research Institute.

1 Kane JM. Pharmacologic treatment of schizophrenia. Biol Psychiatry 1999;46:1396-408.

2 Allison DB, Mentore JL, Heo M, Chandler LP, Cappelleri JC, Infante MC, et al. Antipsychotic-induced weight gain: a comprehensive research synthesis. Am J Psychiatry 1999;156:1686-96.

3 Wirshing DA, Spellberg BJ, Erhart SM, Marder SR, Wirshing WC. Novel antipsychotics and new onset diabetes. Biol Psychiatry 1998;44:778-83.

4 Meyer JM. A retrospective comparison of lipid, glucose, and weight changes at one year between olanzapine- and risperidone-treated inpatients. Biol Psychiatry 2001;49(8):536.

5 Coulter DM, Bate A, Meyboom RHB, Lindquist M, Edwards IR. Antipsychotic drugs and heart muscle disorder in international pharmacovigilance: data mining study. BMJ 2001:322:1207-9.

6 Lieberman JA, Golden R, Stroup S, McEvoy J. Drugs of the psychopharmacological revolution in clinical psychiatry. Psychiatr Serv 2000;51:1254-8

7 Fertig MK, Brooks VG, Shelton PS, English CW. Hyperglycemia associated with olanzapine. J Clin Psychiatry 1998;59:687-9.

8 Ober SK, Hudak R, Rusterholtz A. Hyperglycemia and olanzapine. Am J Psychiatry 1999;156:970.

9 Lindenmayer JP, Patel R. Olanzapine-induced ketoacidosis with diabetes mellitus. Am J Psychiatry 1999;156:1471.

10 Rigalleau V, Gatta B, Bonnaud S, Masson M, Bourgeois ML, Vergnot V, et al. Diabetes as a result of atypical antipsychotic drugs: a report of three cases. Diabet Med 2000;17:484-6.

11 Bettinger TL, Mendelson SC, Dorson PG, Crismon ML. Olanzapineinduced glucose dysregulation. Ann Pharmacother 2000;34:865-7.

12 Melkersson KI, Hulting AL, Brismar KE. Elevated levels of insulin, leptin, and blood lipids in olanzapine-treated patients with schizophrenia or related psychoses. J Clin Psychiatry 2000;61:742-9.

13 Caro J, Ward A, Levinton C, Robinson K. Atypical antipsychotics and the risk of developing diabetes. International Society for Pharmacoeconomics and Outcomes Research European meeting, Belgium, 2000. Value Health 2000;3(5):MH2. [Abstract.]

14 Biswas PN, Wilton LV, Pearce GL, Freemantle S, Shakir SAW. The pharmacovigilance of olanzapine: results of a post-marketing surveillance macovigilance of olanzapine: results of a post-marketing surveillance

15 Thonnard-Neuman E. Phenothiazines and diabetes in hospitalized women. Am J Psychiatry 1968;124:978-82.

16 Wynn V. Effects of duration of low-dose contraceptive administration on carbohydrate metabolism. Am J Obstet Gynecol 1982;142:739-46.

17 Isojarvi JI, Rattya VV, Knip M, Koivunen R, Pakarinen AJ, Tekay A, et al. Valproate, lamotrigine, and insulin-medicated risks in women with epilepsy. Ann Neurol 1998;446-51.

18 Walley T, Mantgani A. The UK General Practice Research Database. Lancet 1997;350:1097-9.

19 Lawson DH, Sherman V, Hollowell J. The General Practice Research Database. QJ Med 1998;91:445-52.

$20 \mathrm{Kleinbaum} \mathrm{G.} \mathrm{Analysis} \mathrm{of} \mathrm{matched} \mathrm{data} \mathrm{using} \mathrm{logistic} \mathrm{regression.} \mathrm{In:} \mathrm{Dietz}$ K, Gail M, Krickeberg K, Singer B, eds. Logistic regression: a self-learning text. New York: Springer-Verlag, 1994.

21 Holbrook TL, Barrett-Connor E, Wingard DL. The association of lifetime weight and weight control patterns with diabetes among men and women in an adult community. Int $J$ Obes Relat Metab Disord 1989;13:723-9.

22 Colditz GA, Willett WC, Rotnitzky A, Manson JE. Weight gain as a risk factor for clinical diabetes mellitus in women. Ann Intern Med 1995;122:481-6.

23 Howarth PH, Emanuel MB, Holgate ST. Astemizole, a potent histamine H-1 receptor antagonist: effect on allergic rhinoconjunctivitis, on antigen and histamine induced skin weal response and relationship to serum levels. Br J Clin Pharmacol 1984;18:1-8.

24 Bernstein JG. Psychotropic drug induced weight gain: mechanisms and management. Clin Neuropharmacol 1988;11(suppl 1):S194-206.

25 Goodall E, Oxtoby C, Richards R, Watkinson G, Brown D, Silverstone T. A clinical trial of the efficacy and acceptability of d-fenfluramine in the treatment of neuroleptic-induced obesity. Br J Psychiatry 1988;153:20813. 
26 Ellis S. The metabolic effects of epinephrine and related amines. Pharma col Rev 1965;8:485-542.

27 Melkersson KI, Hulting AL, Brismar KE. Different influences of classical antipsychotics and clozapine on glucose-insulin homeostasis in patients with schizophrenia or related psychosis. J Clin Psychiatry 1999;60:783-91.
28 Nazareth I, King M, Haines A, Rangel L, Myers S. Accuracy of diagnosis on general practice computer system. BMJ 1993;307:32-4.

(Accepted 28 February 2002) 